perceptual integration in human vision. In D. B. Lindsley and F. A. Young (Eds.), Early experience and visual information processing in preceptual and reading disorders. Washington, D.C: National Academy of Sciences, 1970.

Mershon, D. H. Relative contributions of depth and directional adjacency to simultaneous whiteness contrast. Vision Research, 1972, 12, 969-979.

Ogle, K. N. The optical space sense. In H. Davson (Ed.), Visual optics and the optical space sense. Vol. 4. New York: Academic Press, 1962.

Ratliff, F. Mach bands: Quantitative studies on neural networks in the retina. New York: Holden-Day, 1965

Ratliff, F. Coutour and contrast. Scientific American, 1972, 226, 90-103.

Wist, E. R., \& Freund, H. J. The neuronal basis of binocular vision. In $O$. J. Gruesser and R. Klinke (Eds.), Pattern recognition in biological and technical systems. Berlin: Springer-Verlag, 1971.

Wist, E. R., \& Susen, P. Evidence for the role of post-retinal processes in simultaneous contrast. Psychologische Forschung, $1973,36,1-12$.

\section{NOTE}

1. Wist, E. R. Dark adaptation and the Hermann grid illusion. In preparation.

(Received for publication October 29, 1973.)

\title{
Conditioned enhancement as a function of schedule of reinforcement
}

\section{DONALD MELTZER and ROBERT J. HAMM Southern Illinois University, Carbondale, Ill. 62901}

Six rats were conditioned to press a bar for food reinforcement. During each session, there were six presentations of a 2-min light CS followed by a tone. The tone lasted until $2 \mathrm{sec}$ had passed without a barpress. Then a sucrose-solution UCS was presented. When the ratio of response rate during the CS to response rate prior to the $\mathrm{CS}$ was calculated, it was found that the ratio was lowest when barpressing was reinforced on a VI 90-sec schedule, was at an intermediate value when barpressing was reinforced on a VI 4-min schedule, and was highest when barpressing was not reinforced.

Recently a number of experiments have investigated the interaction between operant and respondent behavior using a variation of the Estes \& Skinner (1941) conditioned suppression procedure. In this variation, a positive unconditioned stimulus (UCS) such as food is used rather than a negative UCS such as shock. Several experiments using rats (Brady, 1961), pigeons (Herrnstein \& Morse, 1957; LoLordo, 1971), and monkeys (Henton \& Brady, 1970) have found that operant response rate was higher during the presence of a conditioned stimulus (CS) which preceded a positive UCS than during an interval of equal duration immediately prior to the CS. This phenomenon has been referred to as a conditioned enhancement. However, other experiments, using rats (Azrin \& Hake, 1969; Hake \& Powell, 1970; Van Dyne, 1971) and monkeys (Miczek \& Grossman, 1971; Kelly, 1973) have reported response suppression during the CS. That is, response rate during the CS was lower than response rate during an interval of equal duration immediately prior to the CS. Meltzer \& Brahlek (1970) have shown that CS duration plays a critical role in determining whether conditioned enhancement or suppression occurs. They found that short CS duration resulted in conditioned suppression while long CS durations produced conditioned enhancement.

The effect of CS duration seems to explain some of the differences in the results of these experiments but not all of them. For example, all experiments except the one by LoLordo (1971), in which conditioned enhancement was demonstrated, involved the use of CSs over $1 \mathrm{~min}$ long. All but two of the experiments in which conditioned suppression was demonstrated have used CSs less than 1 min long. One exception was the experiment by Miczek \& Grossman (1971) in which the CS was varied across sessions from $15 \mathrm{sec}$ to $3 \mathrm{~min}$; the other was the experiment by Kelly (1973) in which the CS was $3 \mathrm{~min}$ long. These exceptions to the more common results were interesting because of some of the other experimental parameters which may have produced them. LoLordo (1971) could not produce conditioned suppression in the piegeon with short CSs of 20 -sec duration when the Ss were reinforced on a variable interval (VI) 2-min schedule. Miczek \& Grossman (1971) could not produce conditioned enhancement in the monkey with long CS durations when the Ss were reinforced on a VI 45-sec schedule. The monkeys in Kelly's (1973) experiment also failed to show conditioned enhancement after having been reinforced on a random ratio schedule, even though a VI 1-min schedule was used during test sessions. Although these experiments differed in many important aspects, there is clearly a possibility that frequency of reinforcement is an important variable affecting changes in response rate during the CS. Conditioned suppression did not develop when reinforcement frequency was low, and conditioned enhancement did not develop when reinforcement frequency was high.

Another reason for considering this hypothesis is that response rate during a CS that is followed by an electric shock UCS also changes in part as a function of the schedule of reinforcement. For example, Lyon (1963) studied conditioned suppression in the pigeon and showed that suppression was more complete when the schedule was VI $4 \mathrm{~min}$ than when it was VI $1 \mathrm{~min}$. Blackman (1968) showed that suppression was greatest when both response rate and reinforcement frequency were low. If the processes producing conditioned enhancement are inversely related to the processes producing conditioned suppression, a reduction in 
Table 1

The Effect of Schedule of Reinforcement on Mean Inflection Ratio. Mean Pre-CS Rate, and Mean CS Rate

\begin{tabular}{ccccc}
\hline Sessions & Schedule & $\begin{array}{c}\text { Mean } \\
\text { Inflection } \\
\text { Ratio }\end{array}$ & $\begin{array}{c}\text { Mean } \\
\text { Pre-CS } \\
\text { Rate }\end{array}$ & $\begin{array}{c}\text { Mean } \\
\text { CS } \\
\text { Rate }\end{array}$ \\
\hline $74-79$ & VI 90-sec & .510 & 49.5 & 53.3 \\
$82-87$ & VI 4-min & .572 & 31.1 & 42.9 \\
$90-95$ & VI 90-sec & .526 & 45.7 & 51.3 \\
$98-103$ & VI 4-min & .558 & 32.8 & 42.0 \\
$106-111$ & VI 90-sec & .515 & 39.9 & 44.6 \\
$114-119$ & VI 4-min & .549 & 30.3 & 37.7 \\
\hline
\end{tabular}

reinforcement frequency on a VI schedule should produce an increase in conditioned enhancement.

\section{METHOD \\ Subjects}

Ss were six naive male hooded rats between the ages of 90 and 120 days at the outset of the experiment. Ten days prior to the start of the experiment, Ss were placed and maintained on a 23-h food deprivation schedule. Experimental sessions were scheduled 5 days a week, and Ss were fed immediately after the session or at approximately the same time on weekends. Water was continu ously available in S's home cage.

\section{Apparatus}

Rats were tested in a standard operant conditioning chamber with interior dimensions of $22.2 \times 19.1 \times 19.1 \mathrm{~cm}$. The front wall of the chamber had the following configuration: A response lever $3.2 \mathrm{~cm}$ to the right of center and $6.4 \mathrm{~cm}$ above the grid floor. an opening for access to a liquid dipper $4.4 \mathrm{~cm}$ from the left wall and $2.0 \mathrm{~cm}$ above the floor, a food-pellet cup located $3.0 \mathrm{~cm}$ from the right wall and $3.0 \mathrm{~cm}$ above the floor, and a pilot light located $14.0 \mathrm{~cm}$ above the liquid-dipper opening. Centered on the back wall, a Mallory Sonalert was mounted $13.0 \mathrm{~cm}$ above the floor. A force of approximately $20 \mathrm{~g}$ was needed to operate the lever. The chamber was placed in a ventilated sound-attenuating ice chest. White noise was always present in the experimental room to mask extraneous noises. Electromechanical relay equipment was located in an adjacent control room and controlled stimulus events and response recording.

\section{Procedure}

During preliminary training the response lever was retracted. Ss were given five 30 -min sessions of dipper training. The dipper contained $0.5 \mathrm{cc}$ of $10 \%$ sucrose solution and was available to the $\mathrm{S}$ for $6 \mathrm{sec}$ on a VI 1 -min schedule. Following dipper training, four $30-\mathrm{min}$ sessions of food cup training were conducted. A $45-\mathrm{mg}$ food pellet was delivered into the food cup on a VI 1-min schedule.

Beginning with Session 8-during which the bar was still retracted-the Ss received six CS-UCS pairings each session. The 2-min light CS terminated with the delivery of the 6-sec sucrose-solution UCS. The session length was increased to $50 \mathrm{~min}$, and CSs were presented on a VI 6.5-min schedule. There was a minimum of $5 \mathrm{~min}$ and a maximum of $8 \mathrm{~min}$ between CS presentations. This procedure continued for 10 sessions. CS-UCS presentations then were stopped.

The response lever was inserted into the chamber beginning with Session 18 and was not removed for the rest of the experiment. Sessions 18 and 19 lasted $20 \mathrm{~min}$, and each barpress during those sessions was reinforced with a food pellet. During the next two sessions, responses were reinforced on a VI 45 -sec schedule, and session length was increased to $50 \mathrm{~min}$. The next 18 sessions were conducted with a VI 90-sec schedule.
In the next phase of the experiment, the CS-UCS seyuence Was presented while the rats responded for reinforcement on the VI 90-sec schedule. As during the introduction of the CS-UCS pairings, six CSs were presented on a VI 6.5 -min schedule in each $50-$ min session. The CS-UCS contiguity was modified to eliminate the possibility that a response would immediately precede the delivery of the UCS. Thus, any increase in response rate could not be caused by the UCS's accidentally reinforcing barpressing. To accomplish this, the 2-min CS was followed by a tone with a minimum duration of 2 sec. If a response occurred during the tone, the tone would continue for an additional 2 sec. This constituted a $2-\mathrm{sec}$ period of differential reinforcement of other behaviur (2-sec DRO). The termination of the tone coincided with the delivery of the UCS. Thus there was a minimum delay of $2 \mathrm{sec}$ hetween a barpress and the delivery of the UCS. Forty sessions were :onducted with the CS-DRO-UCS sequence superimposed on the VI 90-sec schedule of reinforcement. After these 40 sessions, the schedule of reinforcement was changed to VI 4-min for eight sessions. From this point on, the schedule of reinforcement was alternated between VI $90 \mathrm{sec}$ and VI $4 \mathrm{~min}$ in blocks of eight sessions until a total of 119 sessions had been reached.

One S was dropped from the experiment after these 119 sessions, and the remaining $S$ s then were exposed to 32 extinction sessions. During the extinction sessions, barpresses were never reinforced with food, but CS-DRO-UCS sequence was unchanged. Ss still received the $10 \%$ sucrose and were still required to make no response during the 2 sec preceding UCS presentation.

Inflection ratios were calculated for each $\mathrm{S}$ in each session. An inflection ratio was defined as the total number of responses during the six 2-min CSs presented during a session divided by the sum of these CS responses plus the total number of responses during the six 2-min intervals which immediately preceded the CSs. An inflection ratio of less than 0.50 indicated that rate during the CS was lower than it had been in the preceding $2 \mathrm{~min}$, and a ratio greater than 0.50 indicated that response rate during the CS was higher than it had been.

\section{RESULTS}

Each S's mean inflection ratio, mean response rate during the pre-CS interval, and mean response rate during the CS was calculated for Sessions 74-79. The same calculations were made for the last six sessions in the successive eight-session blocks during which the schedule alternated between VI $90 \mathrm{sec}$ and VI $4 \mathrm{~min}$. Table 1 shows these data. It can be seen that mean inflection ratio increased each time the schedule was shifted to VI $4 \mathrm{~min}$ and decreased each time the schedule was shifted to VI $90 \mathrm{sec}$. The difference between mean inflection ratios in sessions with different schedules was significant $(F=38.63, \mathrm{df}=1 / 5, \mathrm{p}<.01)$. Repeated exposures to the same schedule had no significant effect on mean inflection ratios. But, as Table 1 shows, there was steady decrease in mean inflection ratio during each successive block of VI 4-min sessions while there was no consistent direction of change during the VI 90 -sec schedules. This interaction between schedules and replications was also significant $(\mathrm{F}=5.41, \mathrm{df}=2 / 10, \mathrm{p}<.01)$.

Table 1 also shows that both the pre-CS and CS response rates were lower during VI 4-min sessions than during VI 90-sec sessions. These differences were highly significant. For pre-CS rate, $F=67.89, \mathrm{df}=1 / 5, \mathrm{p}<.01$; for $\mathrm{CS}$ rate, $\mathrm{F}=13.47, \mathrm{df}=1 / 5, \mathrm{p}<.02$. Pre-CS rate was 
not significantly different in successive blocks of sessions, nor was there any significant interaction between schedule of reinforcement and session blocks. However, mean CS response rate was lower during the last block of sessions than during earlier blocks and the effect of blocks of sessions was significant ( $F=5.30$, df $=2 / 10, p<.05)$. The interaction between session blocks and schedules was not significant.

In spite of the fact that the mean inflection ratio was above 0.50 in all the session blocks shown in Table 1 , there was some question as to whether conditioned enhancement had actually been demonstrated. For instance, in Sessions 74-79, 90-95, 106-111, during which the schedule was VI $90 \mathrm{sec}$, three, five, and four of the six Ss, respectively, had mean inflection ratios above 0.50 . During the first two blocks of VI 4-min sessions shown in Table 1 , all six Ss had mean inflection ratios higher than 0.50 , but in the final block, Sessions 114-119, only four of the six Ss were above 0.50 .

The extinction procedure eliminated all reinforcement for the barpressing response and, based on the effects of the different schedules, was expected to produce higher inflection ratios than were observed when responses were reinforced. As Table 2 shows, the mean inflection ratios during four successive eight-session blocks of extinction were all higher than the mean inflection ratio observed during any block of sessions in which reinforcement was available. Four of the Ss had higher mean inflection ratios during every block of extinction sessions than at any other point in the experiment. The fifth $\mathrm{S}$ had higher mean inflection ratios during the last two blocks of extinction sessions than at any other point in the experiment. It was also the only $\mathrm{S}$ which had a mean inflection ratio during one block of extinction sessions which was below 0.50. All other Ss had mean inflection ratios above 0.50 in every block of extinction sessions, and the fifth $\mathrm{S}$ had mean inflection ratios above 0.50 in three of the four blocks.

Table 2 also shows that mean inflection ratios continued to increase over the extinction sessions and this effect was significant $(F=8.90, d f=3 / 12, p<.01)$. At the same time, both pre-CS and CS rate decreased over blocks of sessions, and these effects were also significant. For pre-CS rate, $\mathrm{F}=9.26, \mathrm{df}=3 / 12, \mathrm{p}<.01$; for $\mathrm{CS}$ rate, $F=6.29, \mathrm{df}=3 / 12, \mathrm{p}<.01$.

\section{DISCUSSION}

Inflection ratios were higher during sessions when the

Table 2

Changes in Inflection Ratio, Mean Pre-CS Rate, and Mean CS Rate During Extinction

\begin{tabular}{cccc}
\hline Sessions & $\begin{array}{c}\text { Mean } \\
\text { Inflection } \\
\text { Ratio }\end{array}$ & $\begin{array}{c}\text { Mean } \\
\text { Pre-CS } \\
\text { Rate }\end{array}$ & $\begin{array}{c}\text { Mean } \\
\text { CS } \\
\text { Rate }\end{array}$ \\
\hline $120-127$ & .639 & 12.9 & 24.5 \\
$128-135$ & .719 & 3.82 & 12.2 \\
$136-143$ & .783 & 1.82 & 9.3 \\
$144-151$ & .789 & 1.35 & 7.4 \\
\hline
\end{tabular}

schedule of reinforcement was VI 4 min as compared to sessions in which the schedule of reinforcement was VI $90 \mathrm{sec}$. This suggests that the inflection ratio was inversely related to reinforcement frequency but, since reinforcement frequency and response rate both differ when different VI schedules are used, it may also mean that the inflection ratio was inversely related to response rate. Support for the latter possibility is provided by the change in inflection ratio over successive blocks of extinction sessions. There was no change in reinforcement frequency during these sessions, but response rate decreased while inflection ratio increased. Still another possibility is that both response rate and reinforcement frequency are important determinants of the inflection ratio.

The fact that these Ss showed conditioned enhancement was particularly striking, since the UCS was contingent upon not responding. One could argue that the conditioned enhancement was produced by responses during the CS, which were accidentally followed by the DRO stimulus. It is impossible to disprove such a hypothesis, but there is no clear support for it either. On the other hand, it might be expected that the reinforcement of nonresponding during the DRO stimulus would generalize to the $\mathrm{CS}$ which preceded it. In that case, the development of conditioned enhancement would have been expecially impressive since the procedure would have served to minimize such an effect. In a somewhat similar experiment, Hake \& Powell (1970) also showed that under some conditions the presentation, at fixed intervals of a short CS followed by brain stimulation, caused a suppression of responding during the CS but increased response rates just before the CS. Both experiments tend to suggest that conditioned enhancement cannot be considered an example of superstitious conditioning.

\section{REFERENCES}

Azrin, N. R., \& Hake, D. F. Positive conditioned suppression Conditioned suppression using positive reinforcers as the unconditioned stimuli. Journal of the Experimental A nalysis of Behavior, 1969, 12, 167-173.

Blackman, D. Response rate, reinforcement frequency and conditioned suppression. Journal of the Experimental Analysis of Behavior, 1968, 11, 503-516.

Brady, J. V. Motivation-emotion factors and intracranial self-stimulation. In D. E. Sheer. (Ed.), Electrical stimulation of the brain. Austin: University of Texas Press, 1961.

Estes, W. K., \& Skinner, B. F. Some qualitative properties of anxiety. Journal of Experimental Psychology, 1941, 29, 390-400.

Hake, D. R., \& Powell, J. Positive reinforcement and suppression from the same occurrence of the unconditioned stimulus in a positive conditioned suppression procedure. Journal of the Experimental Analy sis of Behavior, 1970, 14, 247-257.

Henton, W. W., \& Brady, J. V. Operant acceleration during a pre-reward stimulus. Journal of the Experimental Analysis of Behavior, 1970, 13, 205-210.

Herrustein, R. J., \& Morse, W. H. Some effects of response independent positive reinforcement on maintained operant behavior. Journal of Comparative \& Physiological Psychology, $1957,50,461-467$.

Kelly, D. D. Long-term prereward suppression in monkeys unaccompanied by cardiovascular conditioning. Journal of the Experimental Analy sis of Behavior, 1973, 20, 93-104.

LoLordo, V. M. Facilitation of food reinforced responding by a signal for response-independent food. Journal of the Experimental Analysis of Behavior, 1971, 15, 49-56.

Lyon, D. O. Frequency of reinforcement as a parameter of conditioned suppression. Journal of the Experimental Analy sis of Behavior, 1963, 6, 95-98.

Meltzer, D., \& Brahlek, J. A. Conditioned suppression and conditioned enhancement with the same positive UCS: An effect of CS duration. Journal of the Experimental Analysis of Behavior, 1970, 13, 67-74.

Miczek, K. A., \& Grossman, S. Positive conditioned suppression: Effects of CS duration. Journal of the Experimental Analy sis of Behavior, 1971, 15, 243-247.

Van Dyne, G. C. Conditioned suppression with a positive US in the rat. Journal of Comparative \& Physiological Psychology, $1971,77,131-135$.

(Received for publication October 27, 1973.) 